\title{
Ciudad Difusa y Archipiélago Metropolitano
}

R cado pelo autor, Francesco Indovina (ed.) (2004), La Ciudad de Baja Densidad, editado pela Deputació de Barcelona. A obra é constituída por um conjunto de materiais, aprofundados e revistos, que foram apresentados num curso para quadros de administração e investigadores em 2004 com o mesmo título. O curso foi dirigido por Jordi Bertran e Francesco Indovina. Deste modo, é necessário situar o texto, que se apresenta sem modificações nem reelaborações, no momento e no contexto em que foi produzido, permitindo igualmente que se compreendam algumas das referências nele contidas.

Palavras-chave: Urbanizaçâo difusa; Cidade de cidades; Arquipélago metropolitano.

\section{Presentación: Antes de la ciudad difusa}

El curso organizado por la Diputación de Barcelona y coordinado por Jordi Bertran y por mí mismo, La ciudad de baja densidad: lógicas, gestión y contención, abordó un fenómeno de organización territorial cada vez más generalizado y que plantea importantes problemas de gestión. Los materiales elaborados para dicho curso, que aquí se publican, tenían que responder básicamente a la siguiente pregunta: cuál es el coste económico, social y medioambiental de esta nueva organización territorial, que definíamos - sin que hubiera un consenso general entre los participantes - como ciudad pero de baja densidad, es decir, donde la baja densidad se conjugaba con el concepto de ciudad. Había además que poner sobre la mesa las "políticas de contención", cuestión ésta que revelaba que nos hallábamos ante una configuración espacial que planteaba problemas y merecía ser corregida mediante políticas específicas. El ámbito territorial de referencia fue preferentemente España y, sobre todo, Cataluña, pero en temas concretos se remitió también a casos de otros países y regiones europeas.

Para cumplir con las finalidades del curso, se optó por encargar la preparación de un dossier sobre cada tema con abundante documentación, que tras ser presentado fue sometido a un debate crítico. Del interés y riqueza de dicho material da fe la presente publicación, que esperamos sea apreciada por los lectores.

A continuación intentaremos esbozar el telón de fondo del fenómeno, una especie de esquema dentro del que debería ser más fácil situar las distintas cuestiones. Esbozar este marco de referencia servirá asimismo para sacar a la luz algunas cuestiones teóricas y metodológicas, divergencias interpretativas y las que podríamos definir como carencias disciplinarias. No haremos, pues, una exposición sintética del material que contiene el volumen, sino que intentaremos ofrecer un cuadro general que ayude a entender mejor el fenómeno.

El fenómeno sobre el que trató el curso resulta importante desde varios puntos de vista: su consistencia, sus motivaciones, sus consecuencias, su relación con la planificación, sus políticas de control. Aspectos todos ellos importantes, pero la verdadera trascendencia del fenómeno radica en su impacto sobre la ciudad: la que, por tradición, se sigue considerando la "forma" ciudad objeto de conflicto en tanto en cuanto los que durante mucho tiempo han sido considerados "fragmentos", improcedentes ocupaciones del territorio (del campo), han terminado por adquirir una fisionomía urbana aun careciendo de todos los rasgos fisicos y morfológicos de la ciudad, es de-

\footnotetext{
"Istituto Universitario di Architettura Di Venezia.
} 
cir, aun careciendo de intensidad, densidad y falta de solución de continuidad. Por supuesto, ahora y siempre cada ciudad ha sido distinta de las otras: no es esta la cuestión, porque cada una dentro de sus diferencias tenía en común con todas las demás unos rasgos generales fisico-morfológicos y sobre todo un "limite", y el fenómeno que aquí nos incumbe rompe con esta tradición afirmando al mismo tiempo un perfil urbano. Es algo que altera materialmente la organización y el orden espacial, da una configuración distinta a intereses y modelos de vida, obliga a enfocar de otra manera la política territorial y afecta de lleno a la cultura urbanística.

Es preciso puntualizar que el fenómeno objeto de nuestro interés, la creación de una condición urbana distinta a la de la tradicional ciudad compacta, la que siempre hemos conocido, concierne al escenario europeo, a sus grandes países, y constituye una tendencia que se halla en un estadio más o menos avanzado, que avanza a mayor o menor velocidad, en función de las condiciones específicas - de desarrollo y de tipo de desarrollo, entre otras - de cada país en concreto y de cada una de sus regiones. La tendencia, en cualquier caso, está delineada, tal como lo ha documentado la exposición Explosión de la Ciudad; tendencia, debemos recalcar, que no puede asimilarse a otros casos, aparentemente similares, como el de Norteamérica, que ofrecen causas y resultados totalmente diferentes.

Para ir aclarando algunas de estas cuestiones, será útil empezar por presentar y especificar el fenómeno, su evolución y por determinar las causas generales que pueden explicarlo.

El fenómeno de la urbanización del campo, en esta segunda posguerra, se presenta poco homogéneo: distintos han sido a lo largo de los anos, los tipos de asentamientos, cuyas fases de desarrollo no han coincidido en los distintos países. Si hacemos un desglose del fenómeno se pueden distinguir por lo menos los siguientes aspectos:

- hay que vincular estrechamente la urbanización del campo con la devaluación de la actividad agrícola. Donde la actividad agrícola sigue produciendo un rendimiento, el campo, por decirlo así, resiste. Es la pérdida de rentabilidad lo que transforma el territorio agrícola en una zona a la espera de ser utilizada de otra forma $y$, pre- ferentemente, de ser edificada. A su vez, la posibilidad de que una zona tenga perspectivas de utilizarse para la edificación puede determinar su pérdida de potencial agrícola (no se hacen inversiones, no se buscan productos que puedan aumentar la rentabilidad, etc.). No estamos diciendo que dicha "espera" sea la causa de la urbanización difusa, sino más bien que esta posibilidad ha facilitado el proceso;

- no se debe olvidar que los grandes procesos migratorios, especialmente la emigración interior, que han caracterizado a numerosos países europeos, sobre todo del sur de Europa, han determinado una fuerte presión sobre el mercado inmobiliario, causa - entre otros aspectos - de la dinámica creciente de los precios de viviendas y terrenos, así como una apreciable densificación y crecimiento de las ciudades;

- los asentamientos de cierta consistencia fuera de la ciudad, caracterizados por la baja densidad (un conjunto de casas unifamiliares con jardín, garaje, etc.), son el resultado de una promoción inmobiliaria especulativa que, por un lado, aprovecha los bajos precios de los terrenos agrícolas y, por otro, satisface y explota el deseo de las familias, por lo común de clase media-alta, de hacer realidad su ideal de vivienda: un chalé independiente, en medio de la naturaleza, con piscina, etc. (si bien después la realidad no se corresponde con ese ideal). La "ciudad jardín”, ya de por sí discutible, se transforma en el asentamiento, aislado en el campo, de una serie de casitas individuales poco distantes entre sí, promocionadas con el slogan "a pocos minutos del centro de la ciudad" (en coche, evidentemente), viaje que la congestión viaria convierte en cansancio, stress y tiempo;

- la diseminación de casas individuales en el territorio es el resultado de dos fenómenos distintos pero convergentes. Por un lado, es consecuencia de la mejora de las condiciones de vida de los miembros más jóvenes de las familias campesinas, que, tras encontrar empleo en distintos sectores (industria, sobre todo) y ver aumentados 
sus recursos económicos levantan, en el terreno propiedad de la familia (el viejo campo en parte abandonado), una nueva vivienda, muy a menudo autoconstruida con la ayuda de parientes y amigos. Por otro lado, familias cansadas de vivir en la ciudad concentrada y reacias a abrazar las ofertas de los grandes asentamientos especulativos, entre otras cosas por disponer de recursos económicos insuficientes, se hacen empresarios autónomos y construyen en el campo, allí donde resulta posible.

En definitiva, éste es el circuito: desarrollo económico (industrial) de la ciudad, emigración del campo a la ciudad, crecimiento de la densidad, aumento de los precios inmobiliarios y predisposición, por decirlo así, del campo a dejarse urbanizar, constituyen los ingredientes que dieron inicio a una transformación del territorio que ya no se ha detenido. Pero son otros, y no menos poderosos, los factores que han acentuado este proceso. De forma sucinta los podemos resumir en:

- el éxito de la ciudad (concentrada), es decir, su desarrollo produce un incremento de la renta y por consiguiente un aumento en el coste de la vida La ciudad (concentrada) es cada vez más incompatible con las actividades económicas que tienen bajo añadido y con las familias de renta baja o media-baja. Unas y otras son empujadas a marcharse, la situación las lleva a buscarse una colocación diferente en el espacio;

- el efecto de la tecnología sobre las actividades productiva que genera la desarticulación de la producción en unidades más pequeñas y separadas pero integradas en un único proceso productivo, la posibilidad de controlar y gestionar la producción a distancia y la facilidad para externalizar segmentos de producción y de servicios, ha reducido considerablemente el valor positivo y el interés por la aglomeración. Estar en la ciudad termina por dejar de ser una ventaja para convertirse en un inconveniente (mayores costes, congestión, retrasos, posibles dificultades para ampliar las instalaciones, etc); en cambio, alejarse, o por lo menos alejar la producción, elimina estos inconvenientes dando a la vez la posibilidad de sacar partido del precio a menudo alto de las áreas abandonadas. Además, ¿por qué no decirlo?, la diseminación por el territorio ofrece la ventaja adicional de "menores controles" (por ejemplo medioambientales);

- el desarrollo de la pequeña y mediana empresa, fruto tanto del uso inteligente de nuevas tecnologías como de una notable capacidad empresarial (a menudo de la unión de ambos), junto con la difusión de los «distritos industriales», constituye una de las principales novedades del desarrollo productivo de la posguerra. La pequeña y mediana empresa, con frecuencia ensalzada como el standard de dimensiones ideales para el desarrollo futuro, o bien vituperada por su escasa capacidad de investigación y de medirse con los nuevos fenómenos del mercado internacional, constituye uno de los «sujetos» que en mayor grado han tendido a ocupar el territorio extra-urbano. La explicación reside en varios factores, que van desde el bajo coste de los terrenos hasta el origen no urbano de muchos de estos empresarios, desde la evolución que han sufrido las actividades de trabajo a domicilio localizadas principalmente en el campo hasta la utilización de edificios de uso agrícola como primer asentamiento, etc. Sea cual fuere la motivación, el dato que importa, es su destacada presencia dentro del campo urbanizado;

- los nuevos estilos de vida, el incremento del tiempo disponible, el incremento del bienestar, una motorización enormemente extendida, etc., determinan, como hemos dicho, la realización del deseo de un nuevo modelo de vivienda (la casa unifamiliar), pero también determinan nuevas demandas de servicios;

- la demanda de más y nuevos servicios se presenta amplia en su magnitud y articulación (comerciales, de ocio, vida social, deportes, espectáculos, etc.) pero dispersa sobre el territorio, de modo que no sería posible satisfacerla sin la alta motorización 
y la propensión a la movilidad de familias e individuos. Precisamente para responder a estas nuevas demandas el territorio se equipa cada vez más con complejos de servicios integrados: hipermercados junto a centros comerciales y grandes tiendas especializadas, cines multisala junto a pizzerías y salas de juegos, boleras junto a discotecas y gimnasios, etc. La ubicación de dichos complejos obedece a una estrategia de accesibilidad: lo que importa no es que estén cerca del cliente - algo por lo demás imposible -, sino que se pueda llegar a ellos con facilidad. Estos episodios constructivos, con los amplios espacios para aparcar que las acompañan, dibujan un paisaje nuevo;

- observando la transformación del territorio no se puede evitar la alusión a los procesos de fuerte especialización con fines recreativos de la costa y en parte de la montaña.

En definitiva, tensiones, oportunidades, demandas, ocasiones y necesidades han provocado una profunda transformación del territorio, tanto del que se halla bajo el dominio de una gran ciudad - un área metropolitana, para entendernos como de aquellos con poca o ninguna supeditación a la metrópoli.

La simple polaridad ciudad-campo, vigente hasta el término de la Segunda Guerra Mundial, es hoy sustituida por una variedad de escenarios que reciben distintas denominaciones, pero que podemos resumir en: campo, campo urbanizado, urbanización difusa, ciudad, metrópoli. Cada uno de estos escenarios se caracteriza por una mayor o menor urbanización, por la mayor o menor presencia - podríamos decir - de "objetos", por tener un funcionamiento propio, por proyectar una imagen propia. Una variedad de escenarios que por un lado enriquece las experiencias individuales, pero por otro provoca impactos no siempre positivos sobre el medio ambiente, sobre el paisaje, sobre la organización de los servicios, sobre la funcionalidad de la administración.

En este punto de nuestra descripción del telón de fondo, tropezamos con el primer escollo metodológico: ¿cómo identificamos o a cuál de los posibles escenarios urbanísticos llamamos ciudad de baja densidad? Desde la década de 1990, y de forma totalmente indebida, se viene llamando ciudad difusa a todo tipo de urbanización del campo de dimensión consistente. Reiteradamente ha sido preciso aclarar que la dimensión de la difusión no tiene nada de calificación de ciudad. La ciudad difusa, fórmula que como es obvio constituye una contradicción en términos, se da cuando una determinada y amplia porción de territorio urbanizado ofrece gran abundancia y variedad de funciones, caracterizándose por un amplia dotación de servicios pese a que estén esparcidos por el territorio, y cuando - éste es el principal requisito - es utilizada por la población allí asentada como si de una ciudad se tratara. Es la característica de los equipamientos y de su uso lo que justifica dicha denominación.

Con este breve paréntesis pretendemos asimismo combatir el uso igualmente desviado que se hace de la locución ciudad de baja densidad con referencia a todo asentamiento caracterizado por una baja densidad. La ciudad de baja densidad tiene que ser a la vez ciudad y caracterizarse por ser de baja densidad; se define por la presencia de la complejidad urbana (funciones y equipamientos) en un área extensa y por un uso urbano de dicha área por parte de los ciudadanos. En el resto de casos tenemos distintos niveles de urbanización. Podríamos afirmar que ciudad de baja densidad y ciudad difusa vienen a ser las fórmulas utilizadas en dos lenguas distintas para nombrar un mismo fenómeno, si bien una tiende a destacar un elemento propio de la arquitectura y la construcción, la baja densidad, y la otra un elemento relativo a la organización de lo espacio, la difusión.

El escollo metodólogico radica precisamente en el hecho de que no toda la cultura urbanística, la que se ocupa de la ciudad y el territorio a distintos niveles, considera que pueda atribuirse al fenómeno, del que aquí tratamos, el rango de ciudad, mientras que hay quien, aun reconociéndole por lo menos en parte tal rango, considera que el fenómeno es errado y se debe corregir volviendo a meter la ciudad dentro de las murallas. El punto de vista predominante en estas actitudes es, por un lado, "morfológico", y hace referencia, por otro lado, a la "intensidad de la vida urbana", a la vitalidad de sus calles y plazas, a lo imprevisible, etc., elementos que remiten a experiencias del pasado ya inexistentes, o que existen de otra manera, en la ciudad concentrada de hoy en día. Tales puntos 
de vista plantean unos problemas que tienen relevancia únicamente si pueden revelarse operativos en el marco de las transformaciones que están en curso. Ciudad y territorio están y han estado en continua y permanente transformación, y con esa transformación habrá que medirse para corregir, mejorar, dar calidad.

El proceso que estamos analizando tiende a afianzar una demanda de ciudad (si bien, por decirlo así, "fuera de las murallas") en un ámbito territorial. No se trata de un rechazo ni de una tendencia anti-urbana: esta nueva demanda de ciudad más bien hace frente, en el plano de las vivencias individuales, a la fragmentación, que ha sido facilitada por las posibilidades surgidas con el aumento de la movilidad y ha venido determinada por las modificaciones de los procesos productivos, por las innovaciones tecnológicas y los cambios en los estilos de vida. Pero a dicha demanda hay que dar respuestas que estén a la altura de la situación.

Esta situación que genera un nuevo escollo, - digámoslo así - disciplinario: la ciudad difusa; esta fórmula que en cierto modo constituye un oxímoron, desde un punto de vista disciplinario no es algo comprensible, no pertenece a las "figuras" que la disciplina se ha dado como modelos, no existen instrumentos de estudio que permitan explorarla e interpretarla. En definitiva, el fenómeno concreto plantea la necesidad de revisiones disciplinarias, a no ser que se comparta la opinión de que, si la realidad no se ajusta a la teoría, la primera está equivocada o no existe.

Partiendo de esta problemática, es posible distinguir por lo menos tres posiciones que son a la vez teóricas y operativas, y que coinciden las tres, en que abusar del territorio debe considerarse algo negativo, porque da lugar a fenómenos de degradación y no permite un uso sostenible del mismo. A continuación procuraremos delinear el perfil de estas distintas posiciones. Evidentemente, la exposición de tales planteamientos no podrá ser sino muy esquemática y sumaria, sin que deba descartarse la posibilidad de distinguir otras varias posiciones que ocuparían lugares intermedios entre las aquí establecidas. Habida cuenta de la finalidad de estas páginas introductorias creemos poder permitirnos, en cualquier caso, la esquematización.
El primero de los posicionamientos considera el caso de la urbanización que - para simplificar - llamamos "difusa", un fenómeno que hay que extirpar, pues ve en él una negación de la ciudad y, no cree lícito un asentamiento difuso en el territorio que no esté asociado a la actividad agrícola. La solución al problema consiste en volver a meter la ciudad dentro de las murallas, lo que se consigue con varios medios: vínculos y prohibiciones; creando "nuevas ciudades"; mejorando, evidentemente, las condiciones de la vida urbana. A quienes defienden este planteamiento se les escapan - o cuando menos así lo parece - las motivaciones sociales, económicos y culturales que generan el fenómeno, o en todo caso tales motivaciones no les parecen muy relevantes ni, por consiguiente, susceptibles de algún tipo de modificación.

Según el segundo posicionamiento, la realidad es que resulta imposible poner freno alguno a esta dinámica: se da por hecho, en cierto modo, que el "mercado" esta destinado a ganar, asumiéndose la inexorabilidad de la transferencia a nuestros países de modelos pertenecientes a otras culturas urbanas caracterizadas, precisamente, por la difusión. Son imputables a este planteamiento la falta de una interpretación original del fenómeno y la no diferenciación incluso terminológica entre situaciones diferentes, diferentes en la sustancia y en la motivación, como ocurre cuando la "difusión" europea es asimilada al sprawl norteamericano. A partir de aquí, dentro de este marco, se plantea el problema, por un lado, de limitar los daños y, por otro, precisamente para evitar los daños, de ayudar al fenómeno (por ejemplo con las oportunas infraestructuras).

Finalmente, una última línea de opinión, por una parte, considera las motivaciones "fuertes" de dicho proceso no sólo relevantes, sino causa y efecto de las cambiadas condiciones económicas, tecnológicas y culturales; por otra parte, ve con interés la creación auto-organizada de una "condición urbana" y la asume como expresión de una demanda de ciudad. De tales consideraciones deriva un planteamiento de corrección: merecería la pena trabajar para dar cada vez más calidad a estos asentamientos, activando una política de densificación, corrigiendo los fallos, imponiendo reglas y tendiendo a hacer de la ciudad de baja densidad, con mayor determinación si cabe, una ciudad que responda a las novedades pero no acepte pasivamente sus consecuencias. En especial esta 
posición estima necesario pasar de la ciudad autoorganizada a una ciudad determinada por una voluntad colectiva, que cuide del interés general y sea gestionada con respetabilidad política.

Los tres verbos que hemos utilizado, extirpar, ayudar y corregir, bien pueden expresar de forma sintética, aunque esquematizada, la esencia de las tres posiciones.

La que nosotros defendemos con convicción es la tercera. Habida cuenta de la necesidad de ciudad que ponen de relieve estos fenómenos, como la afirmación, en las condiciones actuales, de la dialéctica entre "individuo" y "sociedad" que ha encontrado su máxima expresión en la condición urbana, resulta necesario satisfacer dicha necesidad tomando en consideración los peculiares escenarios que se han creado en estos territorios. Repárese en el hecho de que, si la fragmentación, y por lo tanto la dispersión urbana, implica una afirmación de individualismo (a menudo exasperado), la necesidad de ciudad y la creación, en muchos aspectos auto-organizada, de condiciones y funcionalidad urbanas, puede interpretarle como la expresión de una necesidad (implícita y puede que incluso inconsciente) de sociedad.

Es preciso destacar cómo, en efecto, los procesos de los que estamos hablando son preferentemente el resultado de actividades de auto-organización, en el sentido de que no obedecen a un diseño global, no persiguen ninguna función u objetivo general, sino que responden a opciones individuales, generadas por las propias necesidades y por la interacción independiente entre las opciones de los sujetos individuales. No es la ejecución de un proyecto común, sino más bien el afirmar de intereses individuales. Cuestión ésta que trae a colación un tercer escollo: que se implanto la condición urbana sin un diseño común y de conjunto, por un lado, resulta contradictorio (la ciudad, desde siempre, es el resultado, más o meno satisfactorio, de un diseño) y, por otro, demuestra que la necesidad de ciudad es tan fuerte que se da de algún modo por satisfecha incluso con el desorden de la auto-organización. Este fenómeno no está desprovisto de consecuencias: ante todo, lo que está muy claro es que la condición y funcionalidad urbana que se lleva a cabo es parcial y cubre principalmente las funciones que pueden ser puestas en marcha por los particulares. Es como si la ciudad estuviera manca. Además, el uso de esta ciudad acarrea costes muy elevados, tanto individuales como sociales. Y, por ultimo, resulta menos sostenible que la ciudad concentrada.

Mirando las cosas desde el punto de vista de los individuos, se puede afirmar que la huida, por motivos económicos, medioambientales, sociales y psicológicos, de la insostenibilidad de la condición urbana concentrada hacia un escenario de campo urbanizado no soluciona el problema porque emergen nuevas situaciones negativas: movilidad en aumento, aislamiento, falta de servicios, etc. Precisamente para resolver en parte algunos de estos aspectos la auto-organización tiende hacia la ciudad difusa. Querer aumentar los rasgos urbanos de la ciudad difusa debería constituir hoy el compromiso del urbanismo, lo que implica modificar el procedimiento analítico y la interpretación de los fenómenos, dar sentido a una nueva condición urbana.

En los territorios difusos, incluida la ciudad de baja densidad, lo costes medioambientales en términos de consumo de suelo y energía, contaminación, etc., son superiores a los de la ciudad concentrada, del mismo modo que los costes que las administraciones públicas deben soportar para ofrecer a estos asentamientos los servicios colectivos mínimos resultan hasta cuatro veces superiores a los consumos y costes correspondientes de la ciudad concentrada. Eso sin contar con que el ámbito difuso propicia estilos de vida disipados (basta pensar en el consumo de agua netamente superior, en proporción de 3 a 1). Estos aspectos están bien documentados y analizados en los textos editados dentro del presente volumen.

Estas consideraciones llevarían, casi naturalmente a afirmar la oportunidad de un retorno a la ciudad concentrada. Solución tan obvia como difícil y probablemente negativa. En cuanto a la obviedad no hay más que añadir: la ciudad difusa no ofrece del todo las peculiares condiciones urbanas, es disipadora e insostenible. En cuanto a la dificultad, un proyecto que pretenda volver a meterlo todo "dentro de las murallas" no encara los fenómenos y las fuerzas que han determinado la difusión: modificación de las fuerzas productivas, implantación de nuevos medios y posibilidades tecnológicas, una nueva estructura de los costes de producción y, no menos relevante, los cambios de los estilos de vida. (Véase lo que los materiales documentan sobre la producción de tipologías de 
baja densidad). Se trata de factores que se hallan muy condicionados entre sí y modifican a su vez las condiciones organizativas de los individuos y de la sociedad. La solución resulta además negativa porque somete a una coerción voluntarista un complejo proceso material y una articulada voluntad individual, con resultados seguramente distintos a lo esperados. No se trata de abandonarse a la inexorabilidad de los acontecimientos, sino más bien de incidir sobre ellos de un modo que se revele eficaz.

Resultan evidentes dos cosas: por un lado, la modalidad organizativa de la urbanización difusa no parece aceptable, pues presenta, como se ha dicho, aspectos negativos en distintos ámbitos, si bien responde a exigencias y condiciones específicas tanto en el ámbito de los procesos económicos como en el de los estilos de vida, por otro lado, estos fenómenos deben afrontarse, no pueden ser ni borrados, ni conjurados. El reto que la disciplina, por una parte, y la administraciones públicas, por otra, tienen ante si es el de ofrecer condiciones y funcionalidad urbanas, es decir, ciudad, dentro de las nuevas condiciones y sin dejar de tener en cuenta las tendencias en curso.

Afrontar con éxito este reto significa no solo responder positivamente a la demanda de ciudad que los individuos, necesitados de ciudad, expresan (las formas de la ciudad difusa son una respuesta auto-organizada), sino también crear condiciones favorables al crecimiento económico, la equidad social y el desarrollo cultural.

\section{Conclusión: Después de la ciudad de baja densidad}

En la Introducción del presente volumen hemos expuesto las condiciones y causas principales que han determinado la tendencia a la difusión; los textos siguientes han ilustrado las consecuencias de la urbanización difusa, los aspectos negativos relativos al medio ambiente, los costes sociales, la movilidad, etc. En esta Conclusión queremos intentar responder a estas dos preguntas: ¿qué puede venir después?, ¿cómo alcanzar objetivos encaminados a una mejor habitabilidad? Al intentar responder a estos interrogantes, evidentemente, no pretendemos leer el futuro en una bola de cristal, sino explorar las tendencias en curso y proponer una solución donde pueda hacer factible, justamente, un objetivo de mejor habitabilidad. Los puntos de partida sobre los que no se puede dejar de estar de acuerdo son por lo menos dos, y sobre ellos vale la pena que nos detengamos brevemente.

El primero establece que, como ya hemos argumentado en la Introducción, los fenómenos de difusión o explosión urbana que se están produciendo no conllevan una aversión o rechazo de la condición urbana, sino más bien la materialización de una ciudad distinta que procura conservar de la tradicional la vida social y de relación, la multiplicidad de estímulos y la riqueza cultural, pero no la estructura física. No un movimiento antiurbano, sino la demanda de una necesidad de más ciudad y de otro tipo de ciudad. A esta necesidad dan una respuesta parcial los procesos de auto-organización, que erigen una ciudad manca, con una parte «privada» híper desarrollada y una parte «pública» llena de carencias o, en algún caso, ausente. Son precisamente estas carencias en la parte pública, sea en su vertiente activa de creación de servicios, espacios e infraestructuras, sea en su vertiente más administrativa, de control y regulación, sea en su vertiente proyectual y política de planificación y ayuda a la construcción de un futuro mejor, que determina el manifestarse de todos aquellos perjuicios a los que hemos hecho referencia y que documentan las páginas anteriores, y las que frustran - esto es lo principal - la realización de aquella necesidad de ciudad que expresan los procesos de auto-organización.

El segundo punto sobre el que hay que estar de acuerdo es que las tendencias económicas y sociales que subyacen a la difusión no se han atenuado sino, al contrario, se han acentuado. El desarrollo de la tecnología y los procesos de mundialización provocan una continua reestructuración de las actividades productivas, las grandes ciudades se hacen cada vez más caras, los estilos de vida cambian y los nuevos - los que subyacen a la difusión - se consolidan. La aglomeración pierde cada vez más fuerza, las jerarquías territoriales se debilitan.

Pero no todo es como antes; hay algo que cambia: no sólo las tendencias del pasado se acentúan, sino que se manifiesta algún fenómeno nuevo y la misma demanda de ciudad da pie a algunas modificaciones en los procesos de auto-organización 
- fenómenos y modificaciones que revisten gran interés, entre otras cosas, por las perspectivas en principio positivas que generar.

Determinados estudiosos sostienen que las tendencias en curso, las preferencias de los individuos y las familias empujan hacia una estructura territorial basada en el policentrismo; las "grandes ciudades" ya no representan ni un polo de atracción, ni de desarrollo, ni de eficacia; la estructura territorial evoluciona, en cierto modo espontáneamente, hacia una multiplicidad de ciudades de tamaño medio. Situación juzgada positiva, que bastaría con secundar mediante las políticas oportunas. La objeción que se puede formular a esta tesis concierne precisamente a la interpretación de las tendencias actuales; en concreto, por decirlo de forma muy sintética, no parece que las grandes ciudades hayan perdido su papel: éste sin duda ha cambiado, pero la idea según la cual se está pasando de un territorio fuertemente jerarquizado a un territorio de ciudades medianas sin jerarquías no parece ajustarse a la realidad.

En la fase actual de desarrollo del mercado mundial, alcanzar una posición económica significativa sólo es posible, al parecer, a partir de una "masa critica" mínima; el proceso de difusión se está modificando, pero sólo en parte, en la dirección señalada por una hipótesis policéntrica. En efecto, el policentrismo se caracteriza fundamentalmente, por la autonomía de cada centro, mientras que las nuevas condiciones, en cambio, llevan hacia procesos de integración difusa (procesos de integración que no precisan de proximidad).

Además, a menudo parece que no reflexiona en que individuos y familias, empresas y actividades económicas expresan cada vez más una demanda de servicios de nivel metropolitano, que para ser implantados y progresivamente diferenciados, dadas las demandas cada vez más específicas, requieren un potencial de usuarios (o clientes, según los casos) de dimensión (cuantitativa) metropolitana.

Añádase a esto que las ciudades medianas aparecen cada vez más como realidades organizativas de la vida urbana que reproducen muchos de los defectos de las grandes ciudades sin presentar sus ventajas; a la vez que presentan algunos de los defectos de toda comunidad pequeña sin las virtudes correspondientes. No es casual, pues, que los procesos de auto-organización apunten hacia la que ha sido definida como tendencia a la metropolización: lo "nuevo" a que nos referíamos anteriormente.

En general es posible distinguir en el fenómeno metropolitano un aspecto cuantitativo y uno cualitativo El primero es fácil de definir: una relevante masa de personal y de actividades económicas y de servicios sita en un único territorio fuertemente jerarquizado. El aspecto cualitativo resulta más complejo, simplificando un poco, se puede afirmar que la cantidad, en este caso, genera la calidad: en efecto, los servicios específicos (públicos y privados, destinados a las familias y a las empresas), para ser proporcionados conveniente y eficazmente requieren una demanda de unas dimensiones que sólo la "masa" metropolitana puede garantizar. Pero no es sólo eso: los servicios fuertemente especializados (no destinados a la masa) necesitan también unas dimensiones metropolitanas dentro de las que les sea posible encontrar su segmento (cuantitativamente modesto) de demanda.

En definitiva, un escenario metropolitano posee tanto cantidad como calidad, además de aglomeración y concentración. Esta estructura fuertemente jerarquizada y sujeta a un rígido entramado de relaciones funcionales ha sido rota por los procesos de difusión, analizados en la Introducción, pero con ello ha surgido el riesgo por un lado, de "perder" las funciones metropolitanas y, por otro, para los escenarios de fuerte difusión, de no adquirir nunca funciones metropolitanas. Estos dos peligros parecen exorcizados del proceso de metropolización del territorio.

Estos procesos tienen su origen en estructuras territoriales de "área metropolitana", que en parte se desarticulan mediante una reducción de las jerarquías. En otros casos, encierra un intento por romper con la situación de escenarios pobres en equipamientos, fragmentados o incluso policéntricos, es decir por romper con la apariencia moderada (no sólo en sentido político, sino también cultural, social y económico). La metropolización del territorio se presenta como un factor de crecimiento, una respuesta a los estímulos que ofrecen las nuevas tecnologías, una adecuación a las condiciones económicas determinadas por la ampliación de los mercados, una búsqueda de soluciones para las nuevas y más conscientes exigencias determinadas por los cambios en los estilos de vida, 
así como por nuevas demandas culturales (en el sentido lato).

Para describir sintéticamente el proceso de metropolización hay que empezar por subrayar la relevancia menor de la aglomeración y, por consiguiente, de la concentración. Hemos observado, en la Introducción, cómo en el paso de la urbanización difusa a la ciudad difusa ha sido determinante la localización en el territorio de funciones urbanas comerciales (centros comerciales, pero no únicamente éstos), recreativas (las multi-salas, por ejemplo), deportivas (gimnasios, boleras y similares) etc., cada una de ellas integrada con otros servicios (bares, restaurantes etc.) Según lo dicho anteriormente esta localización (caracterizada por la difusión en el territorio y por la elección de áreas de asentamiento de máxima accesibilidad) constituye, de hecho, el primer núcleo del proceso de metropolización, en la medida en que aparecen como los primeros elementos que responden a una demanda cuantitativa.

Aun así, las nuevas localizaciones de los servicios mencionados no resultan suficientes para determinar el proceso de metropolización (sin duda así marcan el paso de la urbanización difusa a la ciudad difusa). Es preciso observar otro fenómeno. En la fase conocida como de la ciudad difusa, mientras que los servicios banales, los que acabamos de enumerar, se difundían por el territorio, los servicios de "gobierno" (político, administrativo, económico, de las comunicaciones, etc.), junto con los polos de excelencia (de la investigación, de la formación, etc.), permanecían concentrados en las mayores o principales ciudades. Se puede observar ahora como, en consecuencia, por un lado, de la propia difusión y, por otro, de la subida de precios en la gran ciudad concentrada, también estos últimos servicios tienden a trasladarse fuera de las grandes ciudades.

Se advierte, sin embargo, una diferencia fundamental, diferencia que para el tema que nos ocupa reviste cierta importancia. Mientras que los llamados "servicios banales" localizados en el territorio tienden a crear un simulacro de ciudad (baste el ejemplo de los centros comerciales, que en su arquitectura, en su organización de los espacio comunes, en la misma toponimia de sus "plazas" y "calles", etc. procuran aludir a la ciudad) por lo general los polos de excelencia y las funciones de gobierno tienen propensión, en cambio, a localizarse en ciudades, de menor tamaño que las de origen, pero ciudades, como si expresaran una necesidad de localización urbana. Se mueven en esta dirección, por ejemplo, los institutos de formación superior, las sedes de los grandes bancos o compañías de seguros, los grandes hospitales, las propias oficinas administrativas, los centros de investigación, etc. Obviamente, no estamos diciendo que todos los polos de excelencia y centros de gobierno se trasladen, pero sin duda no son ni pocos, ni poco significativos aquellos que lo hacen. Tampoco aquí las experiencias que se registran en los distintos países son homogéneas, pero no cabe duda de que la tendencia exista.

Se trata de un hecho muy importante desde varios puntos de vista: modifica las jerarquías, organiza el territorio en la dirección de un policentrismo integrado, modifica los flujos de movilidad, enriquece el territorio con funciones metropolitanas cada vez mayores.

La metropolización (una tendencia que se manifiesta con velocidades e intensidades distintas en cada contexto) da lugar, más que a un nuevo territorio, a una nueva "metrópolis", quizá el modelo de la ciudad futura, que queda bien representado por la imagen del archipiélago metropolitano.

Las islas de este archipiélago, cada una de las cuales posee su características propias y podríamos decir que su propia personalidad, constituyen en su conjunto una unidad determinada no ya por una “descripción geográfica”, sino más bien por sus relaciones recíprocas (históricas y geológicas, naturales y medioambientales, pero también funcionales, económicas y sociales). En el archipiélago metropolitano cada una de las unidades (que alternativamente pueden estar constituidas por ciudades, pueblos, núcleos, polos especializados, etc.) presenta unos rasgos propios, cuya valencia social y operatividad están estrechamente ligadas a las relaciones que mantiene con todas las demás unidades. A la nueva estructura territorial se la conoce también con el apelativo de "ciudad de ciudades", concepto que puede identificarse con el de archipiélago metropolitano: pero si esta última denominación subraya la dimensión metropolitana, la primera exalta la relación entre ciudades.

Emerge una tendencia que se puede definir como especialización territorialmente articulada: el territorio se organiza a través de "micro" po- 
los especializados (por ejemplo, en comercio, en tiempo libre, en sanidad, en enseñanza superior, etc.), cuyo disfrute no es "local" (de la población que vive en el espacio inmediatamente circundante), sino territorial, es decir, de "área extensa". Cada uno de los "micro" polos sirve a la población de todo ese territorio. Obsérvese, pues, que la jerarquización del territorio metropolitano o los territorios de urbanización difusa convergen hacia una polaridad multiplicada, que por un lado debilita las jerarquías y por otro integra los territorios. Relaciones estrechamente funcionales o preferenciales terminan extendiendo por el territorio una espesa trama de conexiones.

A este proceso contribuyen de forma relevante las redes informáticas: en cierto sentido, esta infraestructura tiene más relevancia para el archipiélago metropolitano que a nivel mundial (las famosas "redes mundiales de ciudades"). En el archipiélago metropolitano cada una de las funciones repartidas por el territorio y cada una de las ciudades y núcleos de población logran desempenar tareas superiores a sus dimensiones en virtud de las relaciones que facilita la red informática. Se produce así una intensificación de las relaciones, una integración operativa y una estructuración de los territorios que dan relieve a las individualidades específicas al mismo tiempo que despliegan relaciones funcionales y de integración (incluso para intentar conquistar un protagonismo internacional como "conjunto").

Causa y efecto del proceso de metropolización es la infraestructuración, no únicamente telemática, del territorio. Es preciso observar que, por lo general, cuando la transformación de la organización territorial es impulsada por los procesos de auto-organización, la infraestructuración del territorio viene detrás, habiendo desempeñado, en cambio, un papel secundario en la dirección del proceso en sí mismo. En otras palabras, han faltado estrategias capaces de corregir, mejorar y poner orden en los procesos de auto-organización (es sin duda el caso de la región italiana del Véneto, pero no el único). El escenario es sin duda más halagüeño en aquellos casos donde el proceso ha sido apoyado por una política adecuada de movilidad colectiva (como en Barcelona).

Ahora ya estamos en condiciones, pues, de enumerar los rasgos específicos de esta nueva organización del territorio: difusión, densificación, especialización articulada, multipolaridad de la excelencia, integración, cada uno de los cuales varía y ofrece particularidades propias en función del contexto específico y del escenario territorial de origen.

Se pone así de manifiesto lo que constituye un importante cambio estructural en la organización del espacio: ya no es la ciudad concentrada el polo de atracción, sino que es más bien el territorio el que lo contiene todo. En su interior conviven varias formas de asentamiento: ciudades concentradas de medio y gran tamaño; centros urbanos de pequeño tamaño; urbanizaciones residenciales sin centro; viviendas diseminadas y aisladas; zonas de asentamientos productivos; fábricas y laboratorios aislados y dispersos; distritos productivos; grandes instalaciones para servicios; polos para la "diversión" y el tiempo libre; polos de excelencia; centros de logística; almacenes, etc.; todo ello integrado en áreas de la funcionalidad y del uso que le dan los habitantes.

Relevantes los flujos de movilidad de las personas. Tanto los flujos obligatorios (trabajo y estudio) como los opcionales (por múltiples motivos: deporte, compras, espectáculos, relaciones sociales, baile, cine, etc.), todos pluridireccionales. No solo eso: mientras que los obligatorios tienden a disminuir en lo que a distancia se refiere, los voluntarios aumentan en cantidad y se hacen cada vez más largos.

Para confirmar la importancia de las redes informáticas, es preciso destacar la multiplicación de flujos inmateriales: flujos de órdenes y de relaciones (administrativos, políticos, financieros, de investigación, científicos, culturales, de información, sociales. etc.). En el archipiélago metropolitano asistimos tanto a flujos físicos en aumento (personas y mercancías), que se adaptan al nuevo contexto, como a flujos inmateriales, también éstos muy en alza, que se suman a los primeros. La jerarquía articulada del territorio se ve puesta a prueba por los cambios que afectan a los flujos de masas (personas y mercancías) y por el relieve creciente de los flujos de potencia (informaciones).

Es el territorio en su unidad el que es valorado por los procesos señalados, mientras que, como es lógico, la distribución de los precios en su interior tiene un carácter diferenciado. Las oportunidades de localización y asentamiento se multiplican en función de los distintos precios de 
los suelos: haciendo un mapa de los mismos en una maqueta tridimensional, la superficie por la cual pasaríamos la mano se presentaría rugosa pero no homogénea, pudiéndose notar múltiples picos y depresiones. En definitiva, estamos ante un escenario con una jerarquía muy articulada, tanto en su conjunto como analizándola por sectores específicos y funciones. Lo que parece predominar es la aparición de territorios organizados de forma integrada y condicionados por una jerarquía soft. Los distintos lugares de ese territorio, con la variedad que les es propia, constituyen las piezas de un mosaico o, mejor dicho, las islas y escollos de un archipiélago.

La tendencia a la metropolización del territorio, como hemos venido reiterando, y a semejanza de la ciudad difusa y de la ciudad de baja densidad, es el resultado de un proceso de auto-organización. No es, pues, un territorio planificado a fin de hacer efectiva una optima organización espacial, sino el que emana de los esfuerzos, decisiones y actuaciones no coordinadas de sujetos en singular (no sólo particulares, sino también entidades e instituciones públicas) interesados cada uno en la realización de sus objetivos.

Este resultado sólo en apariencia constituye una victoria, por decirlo así, de los intereses de los individuos sobre posibles y peligrosas intromisiones políticas. En realidad, los frutos negativos de un proceso de auto-organización no son únicamente de carácter "general", sino que terminan por obstaculizar, hacer ineficaces y más costosas las opciones individuales concretas. Es precisamente la ausencia de un diseño general y común y la falta de coordinación entre dichas opciones lo que genera efectos negativos en el conjunto (desorbitado consumo de suelo; contaminación en aumento; conflictos entre usos alternativos o contiguos del territorio; crisis del "espacio público"; congestión; alto consumo energético, etc.). Simultáneamente, salen a la luz ineficiencias y obstáculos para la realización de las opciones individuales (de familias y empresas), lo que significa que estos sujetos ven reducidas sus "oportunidades".

Lo que resulta evidente es la necesidad de gobernar las transformaciones desde una óptica de gobierno público. Hay que tomar en consideración las expectativas, innovaciones y resistencias a fin de elaborar un proyecto de interés general que garantice una eficaz y efectiva organización del territorio, que cree las condiciones para que los individuos puedan alcanzar (más fácilmente si cabe) sus objetivos personales y, al mismo tiempo, brinde nuevas oportunidades. La planificación territorial puede garantizar el crecimiento económico, la innovación tecnológica y cultural, y el equilibrio social con más eficacia y efectividad que un proceso de auto-organización.

El nivel de planificación apropiado para el archipiélago metropolitano es el de la planificación de área extensa, reinterpretada a la luz del nuevo fenómeno. Aunque pueden indicarse varias experiencias de planificación de área extensa, no parece que exista, ni en el ámbito teórico, ni en el disciplinario, ni en el práctico, un escenario consolidado. Además, las experiencias de planificación de área extensa no han recogido (quizá con alguna excepción) la dimensión territorial del archipiélago metropolitano como un objeto específico en sí mismo.

La planificación de área extensa, dentro del nuevo contexto, debería actuar como una planificación urbana del "nuevo" modelo de ciudad. Su contenido tendrá gran importancia estratégica en la creación de un contexto urbano ampliado; debe ayudar a definir las polaridades articuladas de la totalidad del territorio; debe "contener" todas las políticas públicas (en términos de definición y activación) necesarias para llevar a cabo los objetivos.

Una planificación seria de área extensa podrá determinar un dimensión (masa) eficaz para el posicionamiento del área dentro del contexto internacional globalizado; alcanzar niveles de integración eficientes, facilitando las relaciones dentro del área y entre el área y el exterior; permitirá valorar potenciales y recursos locales, algo muy importante teniendo en cuenta que la valoración de las especificidades locales constituye una posible línea de resistencia a la homologación de la globalización; promover y realizar una organización del territorio efectiva y eficaz (usos correctos del suelo, protección medioambiental, reducción de la contaminación y la congestión, etc.), lo que constituye la premisa para el desarrollo económico y la mejora de la calidad de vida.

No siempre ni en todos los lugares se hallan instituciones de gobierno directo del área del archipiélago metropolitano. En estos casos la planificación de áreas extensas debe fundamentarse en 
la colaboración inter-institucional, que debe poner de relieve los intereses comunes y las ventajas que pueden derivar de ellos. La delimitación del área a la que aplicar esta planificación no puede ser administrativa, sino que más bien debe basarse en la integración de los territorios, del mismo modo que la colaboración inter-institucional puede ser "voluntaria", una especie de proceso de auto-organización institucional, o en algunos casos "promovida" por órganos de gobierno superiores. En la realidad europea se pueden observar tanto formas de gobierno institucional directo como formas de auto-organización institucionales o procesos de promoción. En todos los casos, se trata de encontrar el consenso sobre una línea estratégica para todo el territorio, tanto para su desarrollo como para su organización.

Tal línea estratégica debería ir dirigida a una serie de objetivos, integrados entre si, que, de forma extremadamente simplificada, pueden resumirse, como mínimo, en los siguientes:

- equidad: se trata de prestar atención a los desequilibrios económicos entre las distintas zonas del área, tanto a los ya existentes como a los que puedan manifestarse durante el proceso de metropolización, planteando objetivos de reequilibrio. No deben descuidarse tampoco las diferencias sociales que, obviamente, no pueden ser erradicadas con este instrumento, pero sin duda pueden ser mitigadas interviniendo en la localización, por ejemplo, de servicios sociales;

- densificación: hay que establecer los instrumentos activos (infraestructuras) y pasivos (normas, limitaciones, etc.) oportunos para evitar y reducir procesos que puedan dañar el territorio, así como, al contrario, promover donde sea necesario y posible, instrumentos de compactación de los asentamientos, de recomposición morfológica (que sean de baja densidad no quiere decir que no tengan que ser compactos), y todo tipo de políticas orientadas a reducir las especulaciones que incentivan una difusión sin criterio;

- control de los recursos: hay que activar políticas que estimulen un uso racional de los recursos (sobre todo de los no renovables), que faciliten la producción de ener- gía solar y derivada de biomasas (lo que es mucho más fácil en un contexto de difusión) y fomenten procesos de edificación en los que se adopten criterios eficaces de exposición y se empleen materiales apropiados (también eso resulta más fácil en un escenario difuso);

- desarrollo local: el capital social y los recursos locales pueden, si es preciso, servir de base para proyectos de desarrollo local. Se trata de un aspecto del objetivo que antes hemos indicado bajo el epígrafe de equidad: al fin y al cabo, dicho objetivo resulta irrealizable si no se fomenta el desarrollo económico de todas las zonas comprendidas dentro del área. Cada vez más la elaboración de proyectos de “desarrollo local" da buenos resultados, sobre todo en los países desarrollados; menos, en cambio, cuando se trata de proyectos relativos a áreas tradicionalmente deprimidas. El éxito parece estar asegurado cuando las iniciativas afectan a áreas de crisis industrial, donde el patrimonio consolidado de experiencias, profesionalidad, etc. parece ser una buena oportunidad;

- difusión de la innovación: el proceso de desarrollo económico y social está condicionado cada vez en mayor grado por la investigación científica y la innovación tecnológica. En este campo la planificación de área extensa no puede más que crear - que no es poco - las condiciones para que surjan estructuras y marcos de interrelación oportunos entre la producción científica, su traducción tecnológica y la utilización de esta última en la producción y la vida social (téngase en cuenta que se trata de proyectos complejos, no meramente arquitectónicos);

- progreso cultural: el desarrollo local, la difusión de la innovación y el uso controlado de los recursos deben apoyarse necesariamente en un progreso cultural de la población. No se trata tanto de la preparación profesional, a todos los niveles, de los individuos, como de aumentar el nivel cultural de la población en su conjunto. La "mala" televisión debe tener su contrapeso en estructuras de formación cultural, de 
consumo cultural, de consulta, etc. Dotar el área extensa de adecuadas estructuras culturales será un objetivo de la planificación, mientras que su utilización, las iniciativas activas y demás procesos serán competencia de las comunidades locales;

- recuperación del patrimonio: allí donde sea preciso, el patrimonio histórico y cultural del área extensa deberá ser recuperado para que desempeñe una función activa (ya sea económica o solamente cultural). Deberá ponerse especial atención en el patrimonio "natural": la tendencia del territorio agrícola con rentabilidad modesta a transformarse en áreas a la espera de ser edificadas debe contrarrestarse con la creación de amplias zonas verdes, con la constitución de parques agrícolas, y, si resulta oportuno, con la reforestación, etc. El territorio del área extensa no es todo territorio para edificar; la planificación de área extensa puede fijar las condiciones para una integración equilibrada entre áreas edificadas y áreas no edificadas y áreas verdes desde una óptica de recuperación medioambiental. Las áreas "no" edificadas no tienen por qué ser vistas, ni por los particulares ni por las instituciones públicas, como si estuvieran a la espera de que se borrase aquel "no": pueden desempeñar una función positiva dentro del contexto general precisamente en cuanto no edificadas;

- solución de los conflictos: cada vez más a menudo obras de interés general son objeto de protesta por parte de grupos de ciudadanos o comunidades enteras. De entre estos conflictos, aquellos que contraponen intereses particulares a intereses públicos y colectivos no pueden resolverse sino dentro del derecho que regula y ampara tanto al particular como a la actuación pública. Más compleja resulta la situación en la que surge una confrontación entre la defensa de un interés general local y un interés general de nivel superior. La solución a la contraposición de dos intereses generales no es fácil de encontrar. No obstante, la planificación de área extensa, precisamente en la medida en que establece las distintas modalidades con las que satisfacer los intereses generales de toda el área, puede constituir un instrumento para clarificar las opciones, un medio para mitigar los conflictos o bien el lugar donde alcanzar un entendimiento activando, si es preciso, procesos de compensación;

- infraestructuración: hacer realidad un territorio bien organizado y cumplir los objetivos hasta aquí descritos exige una infraestructura amplia y diversificada. La planificación de áreas extensas reviste en este aspecto una importancia de primer orden, al tiempo que evita que la infraestructura sea la mera respuesta a una "demanda", o que su creación siga una lógica sectorial propia prescindiendo de las modalidades de organización del territorio. Confiere a la infraestructuración del territorio (transportes, movilidad, redes, etc.) un papel estratégico e instrumental precisamente en áreas de la consecución de un territorio bien organizado y funcional.

De lo dicho hasta aquí se deduce con claridad que la planificación está formada por un conjunto de políticas, algunas de las cuales se han indicado indirectamente en los puntos anteriores, mientras que otras más deberán ser elaboradas de acuerdo con necesidades específicas. En cualquier caso, su objetivo general, dentro del marco del archipiélago metropolitano, es el de afirmar una condición urbana extensible a todo el territorio y dotar el área de servicios de nivel metropolitano.

La planificación no es el instrumento mediante el cual una voluntad ciega. encarnada por el poder político, se impone sobre la colectividad y los individuos. Está regida por una opción política elaborada con los ojos bien abiertos a la realidad y relativa al futuro de la comunidad en cuestión. Las modalidades a través de las cuales se alcanza a definir dicho futuro no pueden ser sino las democráticas del debate basado en el conocimiento, cuanto más preciso mejor, de la realidad pasada y presente y de las tendencias en curso. A menudo se utiliza, a estos efectos, la fórmula "objetivos compartidos" o "futuro compartido" donde el énfasis que se pone en el término "compartido" no puede indicar una hipotética unanimidad, sino que debe interpretarse como la activación de un 
procedimiento adecuado de debate que permita al poder político adoptar responsablemente decisiones sabias. Privar al poder político, mediante la participación decisional, de la obligación de escoger y decidir no determina un mejor tono democrático ni del poder ni de la sociedad, ni es garantía de decisiones mejor sopesadas; con ello más bien se da pie a iniciativas ocasionales, no coordinadas, y muy a menudo a la afirmación de intereses parciales fuertes (con capacidad de "voz") contra los intereses más débiles. El equilibrio entre la necesidad de la participación y el debate y la toma de decisiones sensibles pero autónomas por parte de los poderes institucionales debería constituir el compromiso máximo de la política.

La planificación se plantea el objetivo de mejorar la situación de la colectividad. Si dicho objetivo conlleva el sacrificio de algún interés "particular", esto será un mal menor siempre que la planificación no sea autorreferencial y, sobre todo, siempre que ofrezca nuevas oportunidades también para los individuos. El conflicto que podría surgir, y que de hecho se manifiesta, entre los objetivos de la planificación y los de los intereses individuales, no debería tener relevancia alguna si se considera que todo el mundo debería contribuir a la realización del interés general y común que constituye la condición necesaria para que el individuo pueda realizar sus propios objetivos. Las "nuevas oportunidades", reguladas pero no coartadas, de desarrollo económico, de ampliación cultural y de mejora de la calidad de vida que la planificación logra activar son precisamente el terreno para el afirmar de los objetivos y aspiraciones de los individuos.

La planificación no tiene que entenderse come un instrumento, sino sobre todo como una estrategia articulada que se sirve de distintos medios (que van de las normas a los premios, de la comunicación a la organización, de la intervención directa al apoyo parcial de iniciativas individuales, etc.) para alcanzar objetivos explicitados que dibujan un futuro posible. La flexibilidad que tan a menudo se pide no debe aplicarse a los objetivos, ese futuro posible, sino más bien a los instrumentos destinados a llevar a cabo dichos objetivos, lo que conlleva un seguimiento continuo de la situación y de los resultados de las actuaciones, a fin de corregir, reforzar o variar, si es preciso, las formas de intervención. Esto no significa que los objetivos no puedan modificarse, es decir, que se pueda dibujar un futuro posible nuevo y distinto, pero ésta es una operación política y no afecta a la operatividad de los distintos instrumentos.

La planificación de área extensa, como toda planificación que atañe a la ciudad, cuando se efectúa con los procedimientos y objetivos que indicábamos antes sucintamente, ofrece unos resultados que son de gran utilidad precisamente para mejorar la convivencia. Si en la fase actual el empuje de un individualismo desenfrenado hace que el sujeto se sienta "solo contra todos", como si tuviera que encontrar él la solución a cada problema, la organización de la ciudad y del territorio pone en evidencia la falacia de toda hipótesis individualista ante un abanico importante de problemas que los individuos se ven en la circunstancia de tener que afrontar. Resulta evidente, a nivel urbano y de organización del territorio, que precisamente ese abanico de problemas no podrá encontrar solución sino en el ámbito colectivo, ya sea en cuanto a las opciones, a la organización de estructuras específicas o a la formalización (y el respeto) de reglas y normas también específicas, Los comportamientos individuales serán llamados a tener en cuenta la existencia de otros individuos cuyas opciones están condicionadas por relaciones de reciprocidad. Afrontar los temas relativos al funcionamiento de la ciudad y, en este caso concreto, del archipiélago metropolitano, no puede sino empujar a la colectividad a expresar un "individualismo bien temperado", a la búsqueda, por parte del sujeto, de su propia y específica individualidad en relación con la de los demás miembros de la sociedad. El tema del funcionamiento de la ciudad, confrontado con información, participación y realismo puede constituir un fuerte instrumento para que emerja como una necesidad, también para los individuos en singular, la consecución del interés general y la colaboración colectiva; casi un proceso educativo cuya necesidad es muy sentida en el frente de la acción política y de la manifestación de las voluntades individuales.

Para cerrar esta Conclusión quisiéramos poner de relieve un aspecto del proceso de metropolización y constitución del archipiélago metropolitano que reviste cierto interés precisamente desde la perspectiva de la mejoría de la calidad de vida.

Tradicionalmente se ha contrapuesto siempre la "comunidad" a la ciudad y aún más a la 
metrópolis, por considerarse estas últimas como expresión de la "sociedad". A la experiencia "comunitaria" (ya se refiera a las ciudades pequeñas o a los núcleos dispersos) se atribuye una gran fuerza involucradora: todos los habitantes comparten la misma experiencia (social y territorial), todos están implicados y son participes de la misma realidad social; las relaciones acostumbran a tener un cariz afectivo y personal. La experiencia de comunidad exalta la solidaridad entre sus miembros, pero causa a su vez un importante control social; la repetitividad de la experiencia cotidiana y limitados estímulos culturales y sociales, pero también crea un fuerte sentido de pertenencia e identidad.

La experiencia de la metrópolis (sociedad), al contrario, fomenta la libertad individual, la multiplicidad de oportunidades, el lado imprevisible de la experiencia cotidiana, pero también propicia la soledad, el anonimato, la segmentación social, la falta de sentido de pertenencia. A su vez, las relaciones y las opciones no son afectivas, sino de tipo racional.

En suma, y esquematizando mucho, ambas situaciones presentan aspectos positivos y negativos, y terminan por encerrar dentro de un cascarón más o menos definido a quien se ve constreñido a vivir en una comunidad (una pequeña ciudad, por ejemplo) o una metrópoli. No hace falta decir que un análisis detallado obligaría a destacar el peso que tiene en una y otra experiencia la condición social de sus protagonistas individuales. Sin embargo, para los fines que aquí nos proponemos, este aspecto puede tenerse presente sin necesidad de ser analizado al detalle.

La descripción del archipiélago metropolitano que hemos realizado resulta muy interesante precisamente bajo este prisma. La hipótesis que lanzamos es que ésta es una "forma" de organización del territorio que quizá permita conjugar los aspectos positivos tanto de la condición comunitaria como de la metrópoli.

Como hemos visto, la escasa atracción por la aglomeración conduce a una articulación de polos diferenciados y a especializaciones parciales. La población asentada se ve obligada por sus necesidades (de trabajo, estudio, abastecimiento, diversión, cultura, etc.) a multiplicar su movilidad y a hacer uso de todo el territorio. La movilidad ha aumentado y se desarrolla sobre distancias cada vez mayores, al tiempo que permite experiencias nuevas: se incrementan las oportunidades de en- cuentros e intercambios, pero el tiempo "consumido" en desplazamientos crece. El primer dato que conviene recordar es, por lo tanto, el de una utilización metropolitana de todo el territorio por parte de la población, entendiéndose con ello que en el plano dimensional estamos ante una metrópolis ampliada, si bien con una densidad e intensidad no comparables a las de las tradicionales, mientras que en el plano cualitativo la dotación de servicios y funciones disponibles en el territorio ampliado sí es perfectamente comparable a la de una metrópoli (concentrada).

El asentamiento residencial de esta población tiene un carácter articulado, pero con porcentajes importantes en pequeños núcleos, corpúsculos, o en pequeñas ciudades, es decir, en situaciones que podrían calificarse de "comunidad". A su vez, la parte de población establecida en la dispersión en sentido estricto tiende a agregarse funcional, cultural y socialmente a la "comunidad" más cercana. El segundo dato a recordar es pues, el hecho de que la población participa en la "vida de comunidad" (servicios básicos, cafeterías, relaciones de vecindario, contactos de la vida diaria, etc.).

Si se juntan el uso metropolitano del territorio y el asentamiento residencial en comunidad sale a la luz una experiencia de algún modo nueva, que hace suyos los elementos positivos, mientras que se anulan - o por lo menos se ven fuertemente reducidos - los aspectos negativos de uno y otro tipo de asentamiento.

Hay que juzgar, además, en modo muy favorable el debilitamiento de la identidad ligada al lugar. La tendencia a marchitarse en una "identidad local", típica de la experiencia de las comunidades pequeñas, es "corregida", por un lado, por la simultanea experiencia metropolitana y, por otro, por el hecho de que la comunidad local no es, en la mayoría de casos, enteramente autóctona, sino que está formada por personas de distinta procedencia (incluidos porcentajes más o menos altos de inmigrantes extranjeros). En definitiva, estamos ante una distinta tipología de experiencias que tiende a exaltar los elementos positivos de ambos modelos.

Se trata de un efecto nada insignificante o despreciable de los procesos en curso, los cuales requieren cada vez más, para producir sus potenciales resultados positivos, ser gobernados desde una perspectiva colectiva con instrumentos específicos, tal como hemos intentado demostrar. 


\section{Bibliografía}

CASTELLS, M. (1997), The Information Age: Economy, Society and Culture, Blackell, Oxford.

FONT, A., F. Indovina, N. Portas (2004), L'explosió de la ciutat, Coac Publicaciones, Barcelona.

FREGOLENT, L. (2005), Governare la dispersione, Franco Angeli, Milano.

INDOVINA, F. (ed) (1990), La cittá diffusa, DAEST, Venezia.

INDOVINA, F. (1997), "Nuove condizioni ed esigenze per il governo urbano", in C. S. Bertuglia, F. Vaio (eds), La cittá e le sue scienze: la programmazione della cittá, Franco Angeli, Milano.

INDOVINA, F. (1998), "Algunes consideracions sobre la ciutat difusa" in Documentes d'Aanalisi Geográfica, n. ${ }^{\circ} 33$, Barcelona.

INDOVINA, F. (2004), La metropolització del territori. Noves jeraquies territorials" in Font, Indovina, Portas 2004 cit.
INDOVINA, F. (2005), "La nuova dimensione urbana. L'arcipelago metropolitano" in M. Marcelloni (ed) Questioni della cittá contemporanea, Franco Angeli, Milano.

LANZANI, A. (1991) Il territorio al plurale, Franco Angeli, Milano.

LANZANI, A. (2003), I paesaggi Italiani, Meltemi, Roma.

NEL.LO, O. (2001), Cataluña, ciudad de ciudades, Editorial Milenio, Barcelona.

NEL.LO, O. (2003), A qui no!, Empúries Editorial, Barcelona.

MARCELLONI, M. (ed) (2005), Questioni della cittá contemporanea, Franco Angeli, Milano.

SAVINO, M. (1999), "Cittá diffusa, reti, ambienti insediativi: la ricerca di una verosimile definizione dei processi di trasformazione del territorio" in F. Indovina (ed), Territorio, Innovazione, Economia, Pianificazione, Politiche. Vent'anni di ricerca del Daest, Daest Iuav, Venezia.

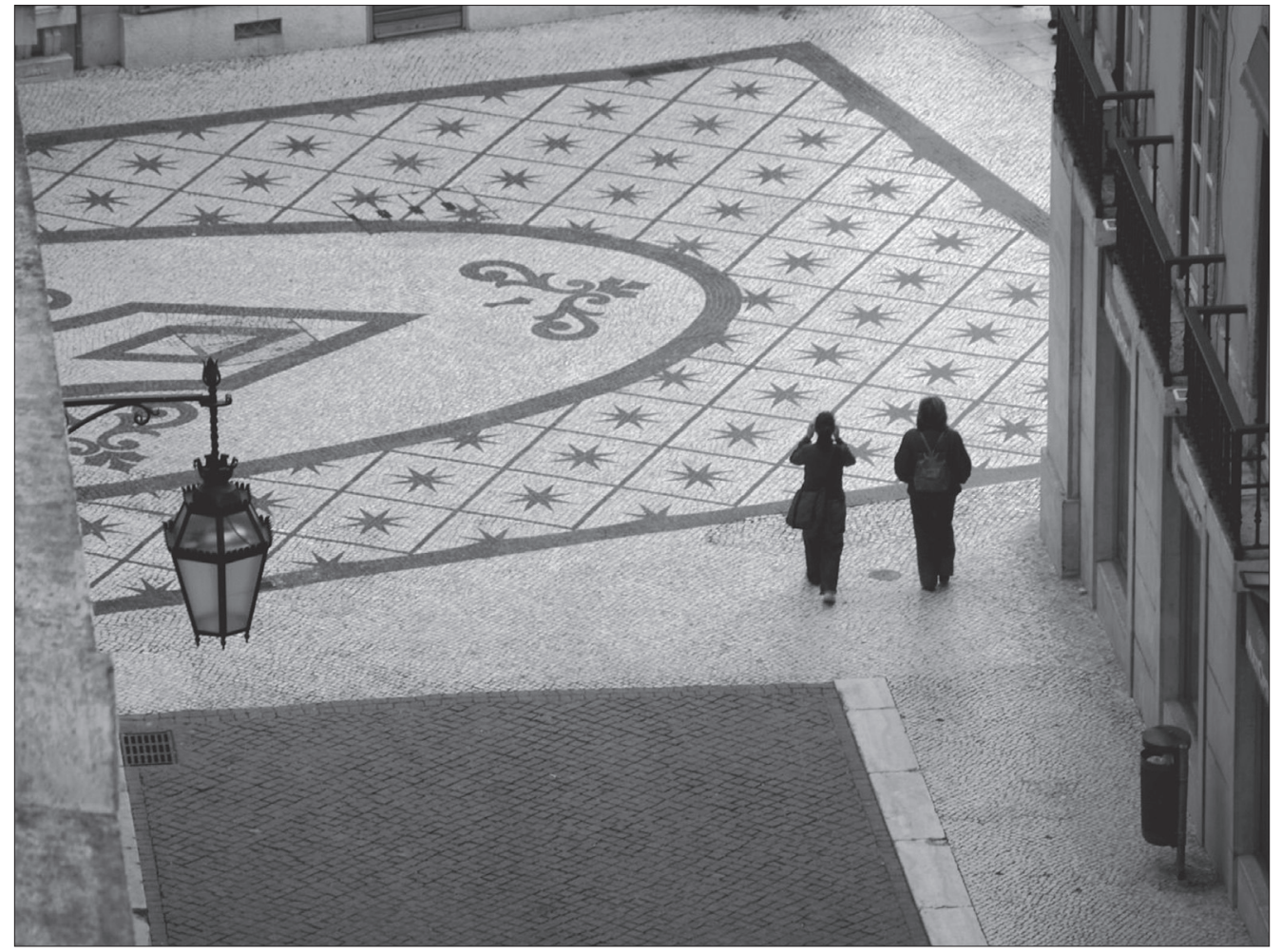

@ Pedro Corte-Real 